\title{
Critically Examine the Idea that Neighbourhoods Characterized by Higher Levels of 'Social Disorganization' are More Prone to Crime
}

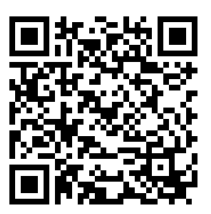

\author{
Ioannis Derziotis* \\ Department of Criminology, University of Surrey, UK
}

Submission: December 15, 2016; Published: January 16, 2017

*Corresponding author: Ioannis Derziotis, Department of Criminology, University of Surrey, Criminal Justice and Social Research, UK, Tel: 6959992080; Email: ioannisderziotis@gmail.com

\section{Introduction}

The first impression when someone hears the phrase "social disorganization", is that neighbourhoods that are socially disorganised will definitely be more prone to crime. It is true that crime is not haphazardly allocated beyond neighbourhoods in a city and doesn't take place evenly in all areas. Instead, it verges to raise in particular locales and not others. Social disorganisation theory considers this fact - the non random distribution of crime- as a departure point for explicating crime [1]. Many people relate social disorganisation with individuals taking or dealing drugs in the streets, fights, high rates of crime, prostitution or different criminal and non criminal acts that generates a feeling of danger and it is seen by neighbourhoods as evidence of failure and collapse in social regulation [2]. In order to confirm or disprove this idea, this essay will try to examine the theories of the Chicago School by analysing their theories and hypothetical models about crime and its connection and reason, to and by different social components. Furthermore, considering researches that have been conducted, an examination of the function of social efficacy in neighbourhoods and the drawbacks of its absence in delinquency and human bonds will be done. Finally, an effort will be made to reinforce this notion by associating it to the "Broken Windows" theory in order to provide an optimum comprehension of the relation amid sociable and physical disorder and crime.

The Chicago School of Criminology contains the work of numerous conspicuous scholars that were concerned of social issues that endured in urban communities. Roberta Ezra Park [3] contended that neighbourhoods are distinctive segments ground on ethnic background, financial status and natural characteristics of fundamental elements of the city. She expressed that urban areas are developed from within to the outside. Few years later, the research of people and the way they generate and communicate with their surroundings was the base, for Park and Burgess [4], that constituted the premature groundwork for what would some years after turn out the social disorganisation theory. Influenced by their backgrounds in human ecology they recommended that metropolitan surroundings sympathize with the same instinctive triggers into human, almost in a similar form as animals distribute with physical surroundings. According to Park and Burgess [4] "the consequence is that the city possesses a moral as well as physical organization, and these two mutually interact in characteristic ways to mould and modify one another".

Furthermore, Park and Burgess conducted the Concentric Zone Theory which emphasized that cities grow outwards from the city centre generating concentric zones, that have unlike ethos and it underlined a procedure of intrusion, supremacy and succession to comprehend city life. The zone out of the inward circle (business locale in the inner part of the city), is termed as "zone in transition" and has high delinquency percentages and various different issues, like poorness and prostitution and as a result the possibility to experience larger amounts of "social disorganisation" and victimization ratio would be higher. However, there were many scholars that criticised this theory supporting that no imaginary standard actually emerges regarding to a consecutive deployment of a city and the "historic inertia argument" which claimed that the spatial and ecological construction of an area at different times relies on the history of the area and on different variables and it is not a natural process as Park and Burgess supported [5,6].

As Louis Wirth supported [7] social disorganisation emerged as an outcome of an absence of consensus and "especially in our modern great cities, where primary group relations are minimal and secondary relations are segmental and usually amoral, we tend to treat aggregations of men who are merely spatially contiguous and functionally interdependent as if they were societies. Under such circumstances, what we are disposed to call social disorganization is rather a situation in which organization in the sense of a common set of norms was never able to develop 
to any appreciable degree". Two years later Shaw and Mackay [8] generated the social disorganisation theory by examining the procedures that create a higher ratio of crime inside "the zone in transition areas". According to Kubrin and Weitzer [9] "Unlike theories centred on "kinds of people" explanations for crime, social disorganization theory focuses on the effects of "kinds of places"-specifically, different types of neighbourhoods -in creating conditions favourable or unfavourable to crime and delinquency". Through their work [8], Juvenile Delinquency and Transition Areas, they found out that very high criminality rates insisted in particular Chicago neighbourhoods for elongate terms of time in spite of transitions in the racial and ethnic synthesis of these communities.

Shaw and Mackay claimed that delinquency is an action of neighbour's dynamics and those social and economic disadvantaged regions were mainly located by immigrants that came later on, provoking ethnic and racial heterogeneity. This ethnic variety caused residential mobility that minimises the chance to create strong bonds among people in a society or a neighbourhood, influencing in a negative way the control of young people by control mechanisms. The non- stop moving in and out of these areas associated with the amputation of ethnicities prompted an inconsistency, which restricted in the settlement of mutual issues connected with high percentages of poverty. Moreover, the potential outcomes for "criminal traditions" to be made essentially expand, creating social transmissions of criminal values, passed through generations. It cannot be denied that physical degeneration and closeness to industrialized districts can affect youth criminality because areas that are nearly the town centre supposed to be less attractive than areas at further distance and their houses environmentally less desirable.

However, it is not only the characteristics or the residential turnover or the nationality of people that live in a neighbourhood the cause of high crime rates but the combination of different social problems such as residential mobility, unemployment, racial heterogeneity and low socialeconomic status. Each of these components conduce to varying means to a neighbourhood's failure to self-control, which may be the cause for growth in delinquency and crime [8-10]. Shaw and Mackay's view that social disorganisation could be analysed by the examination of these three characteristics (economic status, mobility and heterogeneity) and that the combination of these might be the factor for high rates of delinquency was further supported by Blau and Blau [11] who claimed that when economic deprivation is connected with certain characteristics like ethnicity, social disorganisation can be generated. Moreover, Warner and Pierce contended that poverty has a basic role in the relationship between crime and social disorganisation and that social disorganisation is more induced when is taking place in neighbourhoods with high percentages of poverty and unemployment $[11,12]$.
Another theory that can be characterized as an expansion of social disorganisation theory and it is not meant to view individually as an unconditional explanation of the causes of crime, is the" differential association theory". This theory supported that neighbourhoods with high delinquency percentages are not socially disorganised but simply organised in a different way and, as a result, they have alterative values and techniques when it comes to crime. Differential association takes a gander at the distinctions in social gatherings - those that help criminal movement and those that counter it. These two cultures contend inside the neighbourhood to hold or recruit more members. Differential association holds that criminal practices are attained when those clusters that help criminal movement are given more clout than those foundations that counter criminal action. The contrast between those individuals who commit crimes and the individuals who adjust can regularly be traced back to the peer association individuals communicate with the most $[13,14]$.

Social disorganization theory depicted a supreme change in how criminologists viewed delinquency and its causes. Nevertheless, while it did much in altering perceptions, more experimental researches uncovered several evident problems that prevented its helpfulness. As a matter of fact, a huge number of critics left everything except unrelated well into the 1980s [15]. A piece of this feedback focused on the failure to straightforwardly connect the first exogenic variables (economic status, heterogeneity and mobility [8] to delinquency and crime. The original hypothetical model rotated singularly round its three fundamental variables, and whilst these three variables influenced the relation amid a neighbourhood's arrangement and delinquency, a proximate association found hard to display. According to Kornhauser [16] these three variables contribute to the evolution of some other interior determinants that can affect a neighbourhood's capacity to self-control.

Sampson and Groves [17] supporting this theory signified by utilising data from BCS (British Crime Survey) that social disorganization influences the unofficial regulate mechanisms in a way that it raises delinquency and crime percentages. Areas qualities, like family disruption, private portability and structural tightness impoverish unofficial sociable control systems which are blocked by feeble social security brought down neighbourhood connection, namelessness and decreased ability for custody and surveillance. Furthermore, other components like poorness and racial constitution likewise presumably influence unofficial control, despite the fact that their affection is more likely indirect. Citizens in neighbourhoods characterized by family disorder, motility and building consistency are less capable to perform guardianship acts, less possible to report general criminality to the authorities or to intercede in public perturbations and to accept obligation regarding supervision of young people activities. As a result, deviant behaviours are endured and state rules of social control are not efficient. 
The results of the two empirical research that they conducted in UK supported their hypothesis by presenting that social disorganisation affects the intervening variables, since there is very high delinquency in areas with absence of organizational participation, weak social bonds and no supervision in young groups $[9,17]$.

These three intervening variables that emerged through the first original exogenous variables (heterogeneity, mobility and economic status) are frequently mentioned as "collective efficacy". Collective efficacy related to social disorganisation is comprised of two dimensions that are the area's standing of social cohesion and social control [18-20]. Collective efficacy is "a task-specific construct that draws attention to shared expectations and mutual engagement by residents in local social control" and the lack of supervision in youth groups can influence badly the neighbourhood's level of social disorganization $[8,21]$. Social cohesion which can be expressed as a synopsis of altruism and confidence among the members of a society and same values and ideas, can raise the residents ability to participate in the sociable control of individuals in a neighbourhood and decrease delinquency and deviance. By trusting each other within the community, providing help in individuals in times of need and participating in watch programs for the safety of the neighbourhood are means that increase social control [21]. Bursik [15] is further supporting this idea by stating that "breadth and strength of local networks directly affect the effectiveness" of "community social control (p. 527)".

Instances of social, informal control involve residents' actions to anticipate or approve confused and delinquent behaviour through unofficial observation of the neighbourhoods and the streets and immediate interference in problems. Like, for example, investigating individuals about suspecting acts, reprimanding people who are making trouble and advising parents for their children's wrong doings [9]. Sampson's and Grove's theory that neighbourhood net systems, interest in official and deliberate associations and a group's capacity to regulate and control youth groups, clarify a great part of the impact of exogenous qualities on delinquency, was further supported by more empirical research such as Eliot's et al. [22] and Markowitz et al. [23], which provided enough evidence that strong social bonds (including trust and common beliefs) and social control assist in the decrease of delinquency ratio.

At this point it is important to refer to another theory that according some scholars can affect crime rates in a neighbourhood, which is the social capital theory. Social capital according to Coleman [24] refers to the intact sources generated in "relations among persons that facilitate action" for common profits (S100). Furthermore as Seligman supports "The emphasis in modern societies on consensus (is) based on interconnected networks of trust - among citizens, families, voluntary organizations, religious denominations, civic associations, and the like. Similarly the very "legitimation" of modern societies is founded on the "trust" of authority and governments as generalisations" [25]. As a result of this trust among the residents of a neighbourhood some studies have concentrated in the relation between crime and social capital and they found that areas with high strong social capital had reduced crime [26,27]. However, Sampson et al. [18] critiqued that theory saying that social capital doesn't explain how trust is brought into action and how sources (information, rules and commitments) are mobilized to improve sociable control.

As Wilson [28] stated "what many impoverished and dangerous neighbourhoods have in common is a relatively high degree of social integration (high levels of local neighbouring while being relatively isolated from contacts in the broader mainstream society) and low levels of informal social control (feelings that they have little control over their immediate environment including the environment's negative influence on their children)" indicating that social capital is not connected negatively to crime. This motive force that is absent in social capital, that leads people to take actions and rely upon common ideas and beliefs for the common good is collective efficacy, which according to various analyses in Chicago is not only related to neighbourhood crime rates (strong collective efficacy-low crime rates) but also has the ability to decrease the results of condensed disadvantage and residential uncertainty $[29,30]$.

Another theory that is related with collective efficacy is the "broken windows theory". Broken windows theory shows the importance of social disorganisation connected to crime as it recommends that letting disorders either physical (abandoned buildings, broken windows, relinquished vehicles, and empty parcels loaded with garbage)- or social (aggressive vagabonds, loud neighbours and youth groups congregating on road corners) in a neighbourhood uncontrolled, may generate and sustain more crime. Disorder is not straightforwardly connected to crime but prompts expanded fear and withdrawal from inhabitants, which then permits more genuine and serious crime to move in as a result of diminished levels of casual social control. Consider a building with a few broken windows. If the windows are not repaired, the tendency is for vandals to break a few more windows. Eventually, they may even break into the building, and if it's unoccupied, perhaps become squatters or light fires inside.

Or consider a sidewalk. Some litter accumulates. Soon, more litter accumulates. Eventually, people even start leaving bags of trash from take-out restaurants there or even break into cars [31]. As a result when activities like buildings or cars being destroyed and abandoned or graffiti not painted over and people drinking freely in the streets, take place, it is almost certain that further delinquency will be caused. Therefore, the residents of this neighbourhood have the notion that no one cares, that social control doesn't exist and of course they feel unsafe in their own neighbourhood [31]. As Xu, Fiedler and Flaming [32] support "fearful citizens will lock themselves behind closed doors, stay 
off the streets, curtail their normal activities and associations and abandon their basic civic obligations. As social atomization sets in and citizens withdraw physically, they also withdraw from roles of mutual support with fellow citizens on the streets, thereby relinquishing the social controls they formerly helped to maintain within the community. When people stop interacting with one another, social cohesion is out of the question and so is shared willingness to engage in informal social control of public space" [33].

\section{Conclusion}

All the above indicate that "broken windows" theory is directly connected to collective efficacy because disorder represents the collapse of both neighbourhood standards of conduct and official and non-official sociable control, which leads to delinquency [34]. The only way to reverse this situation is collective efficacy in a sense that socially consistent areas with common beliefs and targets, can create high standards of social control and avoid more" break windows" by "repairing them" $[18,29]$. However, it is important to say that some research have critiqued broken windows theory supporting that when the relation between disorder and crime was examined directly and not indirectly (disorder-fear-low social control-crime) as the Broken windows theory did, the results revealed very little to no evidence that disorder affects crime. Even, in that case that the relationship of crime and disorder proved to be forged, collective efficacy interpreted both disorder and delinquency [29,35,36].

Social disorganization theory is a predominant criminological concept and very valuable because it contributes to comprehend the allocation of crime in geographic areas and especially neighbourhoods. It was generated in a period that researchers needed to interpret why and how great proportion of changes in Chicago corresponded to transitions in the delinquency ratio. However, in recent years social disorganization encounters a regeneration and considering the growing deindustrialization of big urban communities, white collar class portability, isolation of the poor and increase of immigrants in many cities around the world - it can be said with certainty that the theory's importance is maybe considerably more powerful nowadays today than when it was initially introduced numerous years back [37].

More, important through the examination of various studies this essay indicated that social disorganization has a great collision in making some neighbourhoods more prone to crime, as it influences many mediating mechanisms that ease delinquency in neighbourhoods. The association of factors like low socioeconomic status, isolation, lack of supervision of youth groups, disorder, weak social bonds and cohesion and indifference for the common good of a neighbourhood cause more crime. Finally, it cannot be denied that the combination of all these theories (social disorganization, broken windows theory, social efficacy, Social Capital) can offer more in depth explanations about why some neighbourhoods are more prone to crime [1].

\section{References}

1. Charis E Kubrin (2000) Racial Heterogeneity and Crime: Measuring Static and Dynamic Effects. Research in Community Sociology 10: 189219.

2. Enrique Gracia, Juan Herrero (2007) Perceived Neighborhood Social Disorder and Attitudes towards Reporting Domestic Violence against Women. Journal of Interpersonal Violence 22(6): 737-752.

3. Robert E Park (1915) The City: Suggestions for the Investigation of Behavior in the City Environment American Journal of Sociology 20: 577-612.

4. Park RE, Burgess EW (1925) The city: Chicago. University of Chicago Press, USA.

5. James A Quinn (1940) The Burgess Zonal Hypothesis and its Critics. American Sociological Review 5(2): 210-218.

6. Alihan M (1938) Social Ecology: A Critical Analysis. Rowen and Littlefield, USA.

7. Louis Wirth (1940) Ideological Aspects of Social Disorganization. American Sociological Review 5(4): 472-482.

8. Shaw CR, McKay HD (1942) Juvenile delinquency and urban areas. University of Chicago Press, USA.

9. Charis E Kubrin, Ronald Weitzer (2003) Retaliatory Homicide: Concentrated Disadvantage and Neighborhood Culture. Social Problems 50(2): 157-180.

10. Rodney Stark (1987) Deviant Places: A Theory of the Ecology of Crime. Criminology 25(4): 893-910.

11. Judith R Blau, Peter M Blau (1982) The cost of inequality: Metropolitan structure and violent crime. American Sociological Review 47(1): 114129.

12. Barbara D Warner, Glenn l Pierce (1993) Reexamining Social Disorganization Theory Using Calls to the Police as a Measure of Crime. Criminology 31(4): 493-517.

13. Edwin H Sutherland (1945) Social Pathology. American Journal of Sociology 50(6): 429-435.

14. Menna William (2009) Evaluating Broken Windows Theory of Crime.

15. Robert J Bursik (1988) Social Disorganization and Theories of Crime and Delinquency: Problems and Prospects. Criminology 26(4): 519551.

16. Ruth Rosner Kornhauser (1975) Social sources of delinquency: An appraisal of analytic models. University of Chicago Press, USA.

17. Sampson Robert J, W Byron Grove (1989) Community structure and crime: Testing social-disorganization theory. American Journal of Sociology 94(4): 774-802.

18. Sampson RJ, Raudenbush SW, Earls F (1997) Neighborhoods and violent Crime: A multilevel study of collective efficacy. Science 277(5328): 918-924.

19. Bonita M Veysey, Steven F Messner (1999) Further testing of social disorganization theory: An elaboration of Sampson and Groves's "Community Structure and Crime". Journal of Research in Crime and Delinquency 36(2).

20. Robert Bursik, Harold G Grasmick (1993) Neighborhoods and crime: The dimensions of effective community control. Lexington Books, USA.

21. R Sampson (2004) Neighborhood and community: Collective efficacy and community safety. New Economy 11: 106-113.

22. Delbert S Elliott, William Julius Wilson, David Huizinga, Robert J Sampson, Amanda Elliott, et al. (1996) The Effects of Neighborhood 
Disadvantage on Adolescent Development. Journal of Research in Crime and Delinquency 33(4): 389-426.

23. Fred E Markowitz, Paul E Bellair, Allen E Liska, Jianhong Liu (2001) Extending social disorganization theory: Modeling the relationships between cohesion, disorder and fear. Criminology 39(2): 293-319.

24. James S Coleman (1988) Social Capital in the Creation of Human Capital. American Journal of Sociology, USA.

25. Adam B Seligman (1997) The problem of trust. Princeton University Press, USA.

26. Dina R Rose, Todd R Clear (1998) Incarceration, Social Capital and Crime: Implications for Social Disorganization Theory. Criminology 36(3): 441-479.

27. Richard Rosenfeld, Steven F Messner, Eric P Baumer (2001) Social Capital and Homicide. Social Forces 80(1): 283-310.

28. William Julius Wilson (1996) When Work Disappears: The world of the new urban poor. Alfred Knopf, USA, p. 63.

29. Sampson Robert J, Stephen W Raudenbush (1999) Systematic social observation of public spaces: A new look at disorder in urban neighborhoods. American Journal of Sociology 105(3): 603-651.

30. Jeffrey D Morenoff, Robert J Sampson, Stephen W Raudenbush (2001) Neighborhood Inequality, Collective Efficacy, and the Spatial Dynamics of Urban Violence. Criminology 39(3): 517-561.
31. Kelling George L, Wilson James Q (1982) Broken Windows: The police and neighborhood safety. Atlantic Monthly 249(3): 29-38.

32. Yili Xu, Mora L Fiedler, Karl H Flaming (2005) Discovering the impact of community policing: The broken windows thesis, collective efficacy and citizens' judgment. Journal of Research in Crime and Delinquency 42(2): $147-186$

33. Robert J Sampson (1988) Local friendship ties and community attachment in mass society: A multi-level systemic model. American Sociological Review 53(5): 766-779.

34. RB Taylor, SA Shumaker (1990) Local crime as a natural hazard: Implications for understanding the relationship between disorder and fear of crime. Am J Community Psychol 18(5): 619-641.

35. Ralph B Taylor (1999) Crime, grime, fear, and decline: a longitudinal look (Research in Brief). National Institute of Justice, USA.

36. Ralph B Taylor (2001) Breaking away from broken windows: Baltimore neighborhoods and the nationwide fight against crime, grime, fear, and decline. Boulder CO: Westview Press, USA.

37. Robert J Sampson, Stephen W Raudenbush (2001) Disorder in urban neighborhoods-Does it Lead to crime? National Institute of Justice: Research in Brief.

\section{Your next submission with Juniper Publishers} will reach you the below assets

- Quality Editorial service

- Swift Peer Review

- Reprints availability

- E-prints Service

- Manuscript Podcast for convenient understanding

- Global attainment for your research

- Manuscript accessibility in different formats

( Pdf, E-pub, Full Text, Audio)

- Unceasing customer service

Track the below URL for one-step submission https://juniperpublishers.com/online-submission.php 